\title{
Histone Deacetylase Inhibitors Relax Mouse Aorta Partly through Their Inhibitory Action on L-Type $\mathrm{Ca}^{2+}$ Channels ${ }^{\llbracket}$
}

\author{
Changbo Zheng, ${ }^{1}$ Mingkui Zhong, ${ }^{1}$ Zenghua Qi, Fan Shen, Qiannan Zhao, Lulu Wu, \\ Yu Huang, Suk-Ying Tsang, and Xiaoqiang Yao
}

Department of Physiology, Anhui Medical University, Hefei, China (M.Z., F.S.); School of Pharmaceutical Science and Yunnan Key Laboratory of Pharmacology for Natural Products, Kunming Medical University, Kunming, Yunnan, China (C.Z.); and School of Biomedical Sciences and Li Ka Shing Institute of Health Science (C.Z., Q.Z., L.W., Y.H., X.Y.), School of Life Sciences (S.-Y.T, Z.Q.), Shenzhen Research Institute (C.Z., Q.Z., L.W., X.Y.), The Chinese University of Hong Kong, Shenzhen, China.

Received May 7, 2017; accepted August 21, 2017

\begin{abstract}
Histone deacetylase (HDAC) inhibitors modulate acetylation/ deacetylation of histone and nonhistone proteins. They have been widely used for cancer treatment. However, there have been only a few studies investigating the effect of HDAC inhibitors on vascular tone regulation, most of which employed chronic treatment with HDAC inhibitors. In the present study, we found that two hydroxamate-based pan-HDAC inhibitors, suberoylanilide hydroxamic acid (SAHA) and trichostatin A (TSA), could partially but acutely relax high extracellular $\mathrm{K}^{+}$-contracted mouse aortas. SAHA and TSA also attenuated the high extracellular $\mathrm{K}^{+}$-induced cytosolic $\mathrm{Ca}^{2+}$ rise and inhibited L-type $\mathrm{Ca}^{2+}$ channel current in whole-cell patch-clamp. These data
\end{abstract}

demonstrate that SAHA could inhibit L-type $\mathrm{Ca}^{2+}$ channels to cause vascular relaxation. In addition, SAHA and TSA dose dependently relaxed the arteries precontracted with phenylephrine. The relaxant effect of SAHA and TSA was greater in phenylephrine-precontracted arteries than in high $\mathrm{K}^{+}$-contracted arteries. Although part of the relaxant effect of SAHA and TSA on phenylephrine-precontracted arteries was related to L-type $\mathrm{Ca}^{2+}$ channels, both agents could also induce relaxation via a mechanism independent of L-type $\mathrm{Ca}^{2+}$ channels. Taken together, HDAC inhibitors SAHA and TSA can acutely relax blood vessels via their inhibitory action on L-type $\mathrm{Ca}^{2+}$ channels and via another L-type $\mathrm{Ca}^{2+}$ channel-independent mechanism.

\section{Introduction}

Histone deacetylases (HDACs) are a family of enzymes that regulate protein activity through removal of acetyl groups (Richardson et al., 2017). A total of 18 histone deacetylases can be grouped into four classes (I, II, III, and IV). The most well known molecular targets of HADCs are the histone proteins that compact DNA in chromatin. Reversible acetylation and deacetylation of histone proteins in chromatin constitutes a major epigenetic mechanism for the control of gene expression. In addition, up to 1750 nonhistone target proteins of HADCs have been identified (Choudhary et al., 2009). It has been suggested that acetylation and deacetylation of these nonhistone proteins may regulate such crucial cellular processes as the cell cycle, cytoskeleton reorganization, endocytosis, and vesicular trafficking (Choudhary et al., 2009). Owing to the

This work was supported by grants from Hong Kong Research Grant Committee (No. AoE/M-05/12, 14118516), RGC-NSFC Joint Grant (No. N_CUHK439/13) and National Natural Science Foundation of China (No. 81070066, 31470912)

${ }^{1}$ C.Z. and M.Z. contributed equally to this work.

https://doi.org/10.1124/jpet.117.242685.

S This article has supplemental material available at jpet.aspetjournals.org. crucial importance of HADC activity in physiologic and pathologic processes, HADC inhibitors have been developed as therapeutic options for a variety of diseases, including cancer, mood disorders, and HIV (Dokmanovic et al., 2007). In an experimental model, HDAC inhibitors have also been shown to be beneficial in arrhythmia, myocardial infraction, hypertension, and atherosclerosis (Eom and Kook, 2014). HDAC inhibitors can be divided into several structural classes, including hydroxamates, cyclic peptides, and others (Dokmanovic et al., 2007). Suberoylanilide hydroxamic acid (SAHA) and trichostatin A (TSA) are hydroxamate-based pan-HDAC inhibitors that inhibit class I and class II HDAC proteins (Dokmanovic et al., 2007). However, their inhibitory potency to different classes of HDAC proteins varies greatly (Ko et al., 2013). Of the two, only SAHA has been approved by the FDA for clinical use, for treatment of cutaneous T-cell lymphoma and multiple myeloma (Dokmanovic et al., 2007).

Only a few studies have investigated the action of HDAC inhibitors in vascular tone control. Most examined the effect of chronic treatment with HDAC inhibitors on vascular tone regulation, but the results are controversial. Usui et al. (2012) showed that chronic treatment of rat mesenteric arteries with TSA for 3 weeks enhanced the endothelium-dependent

ABBREVIATIONS: BAPTA, 1,2-bis(o-aminophenoxy)ethane- $N, N, N^{\prime}, N^{\prime}$-tetraacetic acid; DMSO, dimethyl sulfoxide; HDAC, histone deacetylase; Orai1, calcium release-activated calcium channel protein 1; p66shc, Src homology 2 domain-containing transforming protein C1, MW 66 isoform; RO2959, 2,6-difluoro- $N$-\{5-[4-methyl-1-(5-methyl-thiazol-2-yl)-1,2,5,6-tetrahydro-pyridin-3-yl]-pyrazin-2-yl\}-benzamide hydrochloride; SAHA, suberoylanilide hydroxamic acid; SOCE, store-operated $\mathrm{Ca}^{2+}$ entry; TSA, trichostatin A; U46619, (Z)-7-[(1S,4R,5R,6S)-5-[(E,3S)-3-hydroxyoct-1-enyl]3-oxabicyclo[2.2.1]heptan-6-yl]hept-5-enoic acid. 


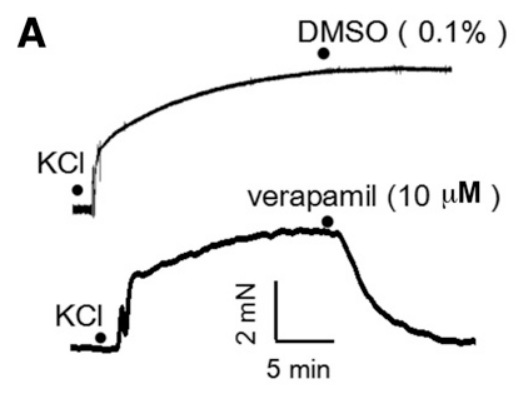

B

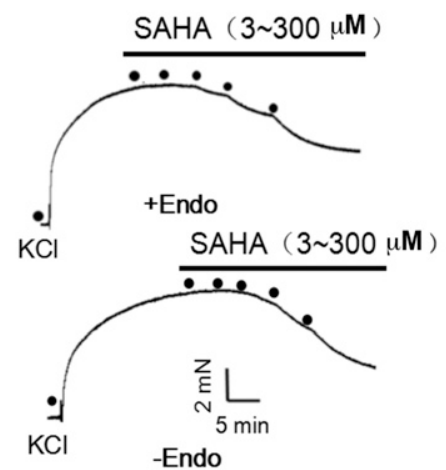

C
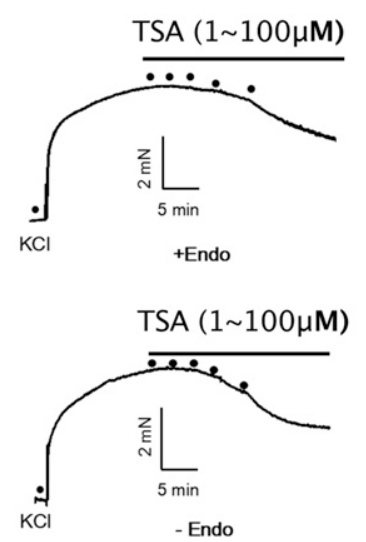
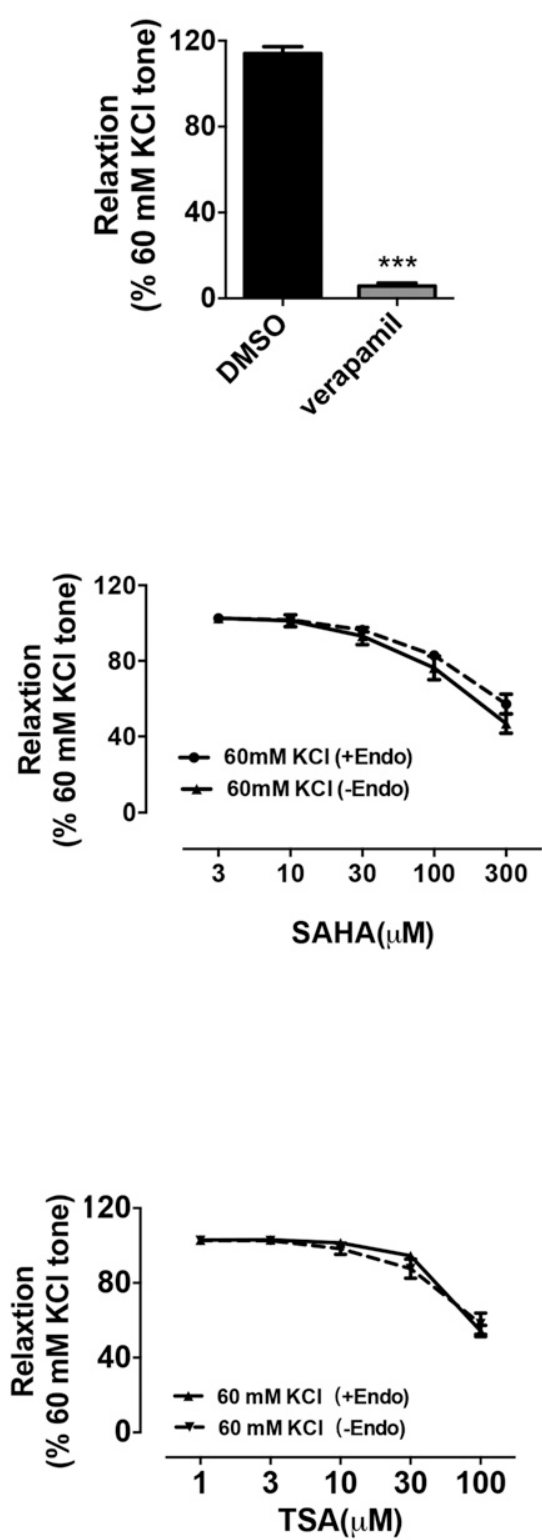

Fig. 1. SAHA and TSA reversed the vascular contraction elicited by high extracellular $\mathrm{K}^{+}$in mouse aortas. (A) Representative traces (left) and summarized data (right) showing verapamil-induced relaxation in the arteries precontracted by $60 \mathrm{mM} \mathrm{KCl}$. The vehicle control (0.1\% DMSO) had no effect. (B and C) The vascular relaxant effect of SAHA (B) and TSA (C) on $60 \mathrm{mM} \mathrm{KCl-precontracted} \mathrm{aortas} \mathrm{with} \mathrm{endothe-}$ lium (+Endo) or without endothelium (-Endo). Representative traces (left) and data summary (right) of relaxing effect are shown. The data are expressed as mean \pm S.E.M. $(n=5)$. $* * * P<0.001$ vs. vehicle (DMSO) control. relaxation and reduced the angiotensin II (Ang II)-induced contraction in spontaneously hypertensive rats. In contrast, several other studies reported that chronic treatment with TSA reduced the endothelium-dependent and endotheliumindependent vascular relaxation (Colussi et al., 2012; Mathews et al., 2014; Pandey et al., 2014). These authors found that, whereas the endothelium-dependent component could be attributed to TSA actions on the expressional level of arginase 2 and nitric oxide synthase (Mathews et al., 2014), the endothelium-independent components might be related to acetylation/deacetylation of such smooth muscle contractile proteins as myosin light chain and smooth muscle actin (Colussi et al., 2012). Interestingly, a recent study also demonstrated an acute effect of HDAC inhibitors on vascular tone. In that study, acute treatment of rat aortic rings with $10 \mu \mathrm{M}$ TSA for 15 minutes substantially reduced Ang II-induced contraction, probably via an inhibitory action of TSA on p66shc phosphorylation in vascular smooth muscle cells (Kang et al., 2015).
In the present study, we aimed to investigate acute effects of HDAC inhibitors on vascular tone. The results show that application of two commonly used HDAC inhibitors, SAHA and TSA, could induce an acute relaxation in high extracellular $\mathrm{K}^{+}$- and phenylephrine-precontracted rat aortic rings. This relaxation was endothelium-independent. $\mathrm{Ca}^{2+}$ influx measurement and whole-cell patch-clamp studies demonstrated that SAHA and TSA inhibit the activity of L-type $\mathrm{Ca}^{2+}$ channels in rat vascular smooth muscle cells.

\section{Material and Methods}

Chemicals. Verapamil, methylene blue, and phenylephrine were from Sigma-Aldrich (St. Louis, MO). SAHA (PubChem CID:5311), TSA (PubChem CID:444732), LBH-589 (PubChem CID:Panobinostat) (6918837), FK228 (romidepsin) (PubChem CID:5352062), and PDX-101 (belinostat) (PubChem CID:6918638) were from Selleckchem (Houston, TX). U46619, SAHA, TSA, LBH-589, FK228, and PDX-101 were dissolved in dimethyl sulfoxide (DMSO), and other drugs were prepared in distilled water. 
A

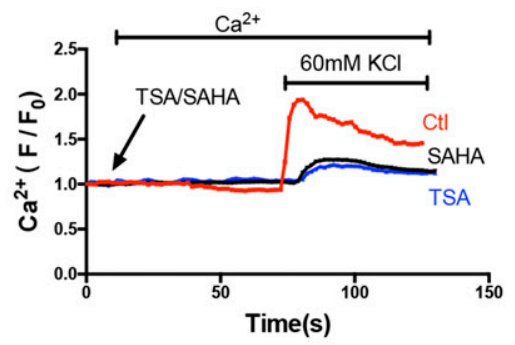

B

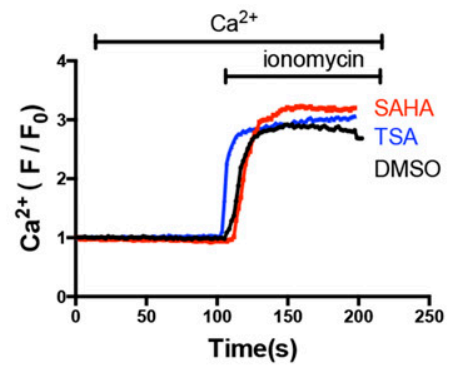

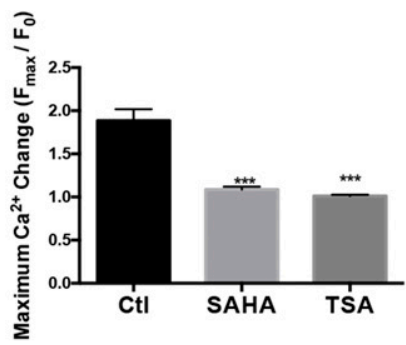

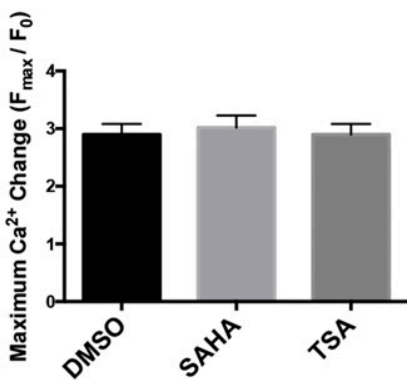

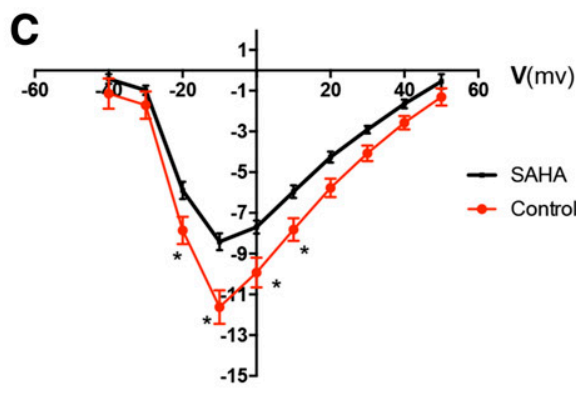

I Ca,L (pA/pF)
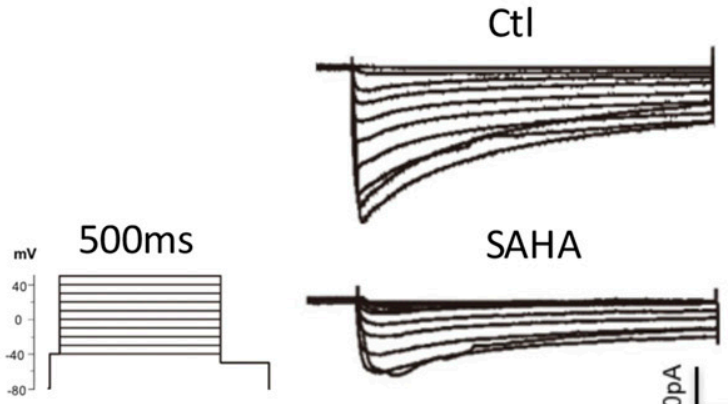

SAHA

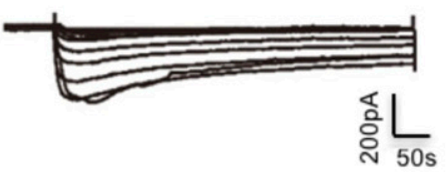

Ctl

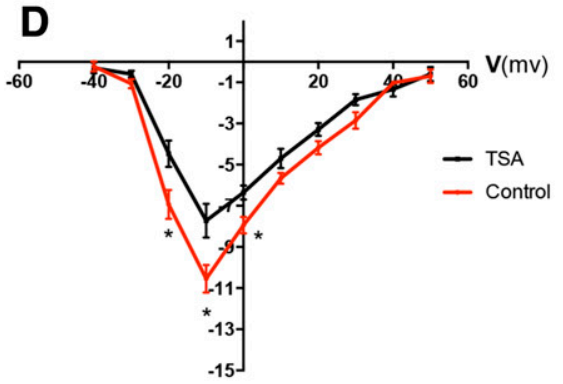

I Ca,L (pA/pF)
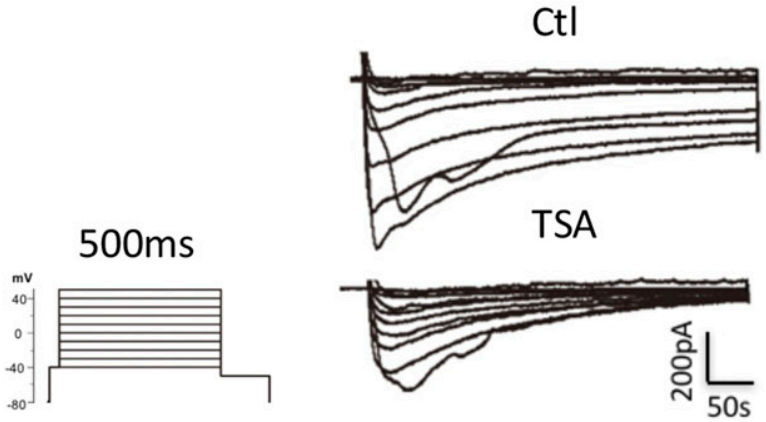

Fig. 2. SAHA and TSA attenuated the high extracellular $\mathrm{K}^{+}$-elicited cytosolic $\mathrm{Ca}^{2+}$ rise and inhibited L-type $\mathrm{Ca}^{2+}$ channel current. (A) Effect of SAHA and TSA on high $\mathrm{K}^{+}$-induced $\mathrm{Ca}^{2+}$ rise. Acutely isolated smooth muscle cells were treated with SAHA/TSA in normal Krebs solution bath, followed by a change to $60 \mathrm{mM}$ $\mathrm{KCl}$ Krebs solution bath, which induced a $\mathrm{Ca}^{2+}$ rise. SAHA/TSA at 300/100 $\mu \mathrm{M}$ was applied about 5 minutes before high $\mathrm{K}^{+}$treatment. Representative traces (left) and data summary (right) of $\mathrm{Ca}^{2+}$ responses are shown. (B) Effect of SAHA and TSA on ionomycin-induced $\mathrm{Ca}^{2+}$ rise. Acutely isolated smooth muscle cells were treated with TSA/SAHA in normal Krebs solution bath, followed by Krebs solution bath with $1 \mu \mathrm{M}$ ionomycin, which induced a Ca ${ }^{2+}$ rise. SAHA/TSA at $300 / 100 \mu \mathrm{M}$ was applied about 5 minutes before ionomycin treatment. Representative traces (left) and data summary (right) of $\mathrm{Ca}^{2+}$ responses are shown. (C and D) Whole-cell current recording in A7r5 cells. Shown are current-voltage (I-V) relationships (left), voltage protocol and representative whole-cell current traces (right) of A7r5 cells with or without SAHA (C) and TSA (D). SAHA/TSA at 300/100 $\mu \mathrm{M}$ was applied about 5 minutes before current recording. The data are expressed as the mean \pm S.E.M. $[n=5$ in $(\mathrm{A}$ and $\mathrm{B}), n=6$ in $(\mathrm{C}$ and D)]. $* P<0.05 ; * * * P<0.001$ vs. vehicle (DMSO) control.

Measurement of Vascular Tension. All animals were obtained from the Laboratory of Animal Services Center, the Chinese University of Hong Kong, Hong Kong, China. The animal experiments were conducted in accordance with the Guide for the Care and Use of Laboratory Animals published by the U.S. National Institutes of Health. Isometric tension of aortic rings were recorded by Multi Wire Myograph
System (Danish Myo Technology A/S, Aarhus, Denmark) as described (Tian et al., 2012). Briefly, male C57 adult mice were killed by carbon dioxide suffocation. After euthanasia, the mouse thoracic aortas were quickly dissected free and cut into 2-mm long rings in ice-cold and oxygenated Krebs buffer, which contained in mM: $119 \mathrm{NaCl}, 4.7 \mathrm{KCl}$, $2.5 \mathrm{CaCl}_{2}, 1 \mathrm{MgCl}_{2}, 25 \mathrm{NaHCO}_{3}, 1.2 \mathrm{KH}_{2} \mathrm{PO}_{4}$, and 11 D-glucose. 
A

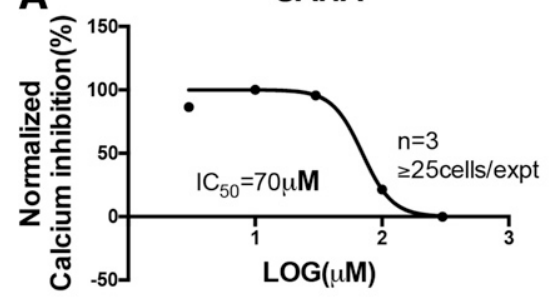

B

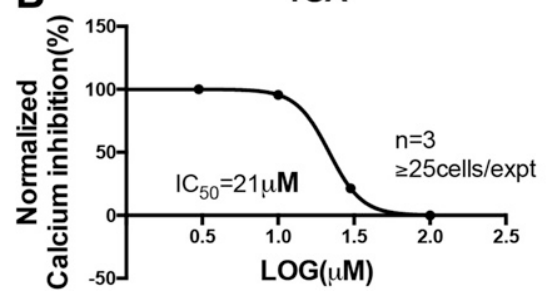

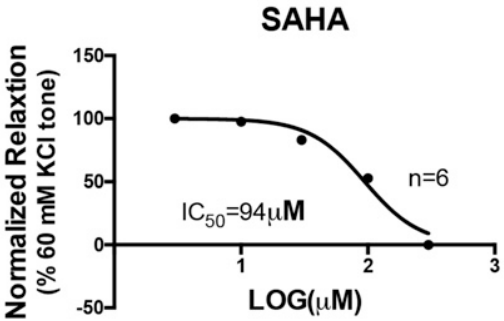

TSA

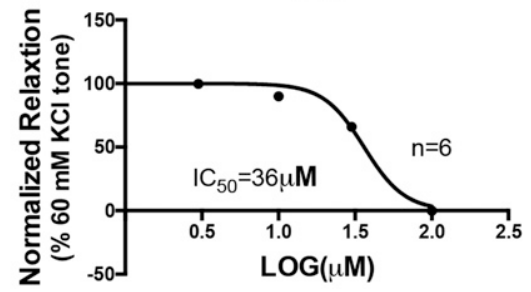

Fig. 3. Comparison of inhibitory potencies of SAHA and TSA on high extracellular $\mathrm{K}^{+}$-induced $\mathrm{Ca}^{2+}$ entry with their vasodilatory potencies. (A) Comparison of dose-response curves and $\mathrm{IC}_{50}$ values of SAHA on $60 \mathrm{mM}$ KCl-induced cytosolic $\mathrm{Ca}^{2+}$ rise in smooth muscle cells (left panel) with vasodilatory action of SAHA in $\mathrm{K}^{+}$-contracted mouse aortas (right panel). (B) Comparison of dose-response curves and $\mathrm{IC}_{50}$ values of TSA on $60 \mathrm{mM}$ KCl-induced cytosolic $\mathrm{Ca}^{2+}$ rise in smooth muscle cells (left panel) with vasodilatory action of TSA in $\mathrm{K}^{+}$-contracted mouse aortas (right panel). The data are expressed as the mean \pm S.E.M. $(n=3-6)$.
The vascular rings were mounted onto two thin stainless-steel holders in a myograph filled with Krebs solution bubbled with $95 \% \mathrm{O}_{2}$ and $5 \% \mathrm{CO}_{2}$ at $37^{\circ} \mathrm{C}$. The optimum baseline tension was set at $3 \mathrm{mN}$. After an equilibration period and $60 \mathrm{mM} \mathrm{KCl}$ solution pretreatment (which contained in mM: $63.7 \mathrm{NaCl}, 60 \mathrm{KCl}, 2.5 \mathrm{CaCl}_{2}, 1 \mathrm{MgCl}_{2}, 25 \mathrm{NaHCO}_{3}$, $1.2 \mathrm{KH}_{2} \mathrm{PO}_{4}$, and $11 \mathrm{D}$-glucose), the rings were exposed to $1 \mu \mathrm{M}$ phenylephrine to test their contractile responses and subsequently challenged with acetylcholine to certify the integrity of endothelium.

Preparation of Acutely Isolated Smooth Muscle Cells. The smooth muscle cells were freshly dispersed as described previously (Eto et al., 2001). Briefly, male C57 adult mice were anesthetized with ether. The aorta was dissected. The connective tissue and the endothelium were carefully removed under microscope and the smooth muscle was cut into 1 - to 2 -mm sections. The tissues were preincubated with oxygenated $\mathrm{Ca}^{2+}$-free phosphate-buffered saline (PBS) with collagenase II $(2 \% \mathrm{w} / \mathrm{v}$ in $1 \times$ PBS) and trypsin $(0.25 \% \mathrm{w} / \mathrm{v})$ for 40 minutes at $18-22^{\circ} \mathrm{C}$, and the smooth muscle was cut into one to two arterial branches and dissected. The tissues were washed three times with oxygenated $\mathrm{Ca}^{2+}$-free PBS and then gently agitated with a blunt-tipped glass pipette until the solution became cloudy. The debris was then removed with a fine $200-\mu \mathrm{m}$ nylon mesh. The cell suspension was stored at $4^{\circ} \mathrm{C}$ and used within 5 hours of cell harvesting.

Preparation of Smooth Muscle Cell Line. An aortic smooth muscle cell line from rat (A7r5) was obtained from the American Type Culture Collection (ATCC). The A7r5 cell line was cultured in 90\% Dulbecco's modified Eagle's medium (Gibco/Thermo Fisher Scientific, Gaithersburg, MD), and 10\% fetal bovine serum (Gibco/Thermo Fisher Scientific) at $37^{\circ} \mathrm{C}$ and $5 \% \mathrm{CO}_{2}$ in air.

Cytosolic $\mathrm{Ca}^{2+}$ Measurement. The cytosolic $\mathrm{Ca}^{2+}$ was measured as described elsewhere (Qi et al., 2015). Briefly, smooth muscle cells were loaded with Fluo-4/AM (Invitrogen/Thermo Fisher Scientific, Waltham, MA) in normal Tyrode's solution that contained in $\mathrm{mM}$ : $140 \mathrm{NaCl}, 5.4 \mathrm{KCl}, 1 \mathrm{MgCl}_{2}, 2 \mathrm{CaCl}_{2}, 5.5$ glucose, and 5 HEPES, $\mathrm{pH}$ 7.4. To deplete intracellular $\mathrm{Ca}^{2+}$ stores, the cells were treated with $4 \mu \mathrm{M}$ thapsigargin in $\mathrm{Ca}^{2+}$-free Tyrode's solution, which contained in mM: $140 \mathrm{NaCl}, 5.4 \mathrm{KCl}, 1 \mathrm{MgCl}_{2}, 5.5$ glucose, 0.2 ethylene glycol tetraacetic acid (EGTA), and 5 HEPES, pH 7.4. Store-operated $\mathrm{Ca}^{2+}$ entry (SOCE) was initiated by the addition of $2 \mathrm{mM} \mathrm{Ca}^{2+}$ to the bath. The real-time fluorescent images were captured every 10 seconds and analyzed by MetaFluor imaging software (Molecular Devices, Sunnyvale, CA).

Patch-Clamp Recording. For whole-cell patch-clamp recordings, single A7r5 smooth muscle cells were seeded on glass coverslips precoated for 30 minutes with Matrigel containing
$50 \mu \mathrm{g} / \mathrm{ml}$ laminin (Corning, Corning, NY) in $0.1 \%$ gelatin (SigmaAldrich). The glass coverslips containing the cells were placed into a room-temperature-recording chamber and perfused continuously with Tyrode's solution, which contained in mM: $140 \mathrm{NaCl}, 1 \mathrm{MgCl}_{2}$, $1.8 \mathrm{CaCl}_{2}, 5.4 \mathrm{KCl}, 10$ glucose, and 5 HEPES, pH adjusted to 7.4 by $\mathrm{NaOH}$. The whole-cell patch-clamp recordings (voltage- and currentclamp configurations) were performed with an Axopatch 200B amplifier (Molecular Devices) and pCLAMP 10.4 software (Molecular Devices). Signals were digitized at $10 \mathrm{kHz}$ and filtered at $2 \mathrm{kHz}$. Microelectrodes (1B150F-4; World Precision Instruments, Sarasota, FL) with resistances of 3-7 M $\Omega$ were pulled from P-97 puller (Sutter Instrument, Novato, CA). L-type $\mathrm{Ca}^{2+}$ current was recorded from single cells with ruptured whole-cell patch-clamp techniques. After establishing patch-clamp, the Tyrode's solution was replaced with the $\mathrm{Ba}^{2+}$-containing solution, which contained in $\mathrm{mM}: 108 \mathrm{NaCl}, 20$ triethylamine (TEA)-Cl, $5.4 \mathrm{CsCl}, 10 \mathrm{BaCl}_{2}, 1 \mathrm{MgCl}_{2}, 5.5$ glucose, and 10 HEPES, $\mathrm{pH}$ adjusted to 7.4 by $\mathrm{NaOH}$. The pipette solution contained in mM: 115 Cs-aspartate, 20 TEA-Cl, $1 \mathrm{MgCl}_{2}$, 5 BAPTA, $3 \mathrm{Mg} \cdot \mathrm{ATP}, 0.2 \mathrm{GTP}$, and $10 \mathrm{HEPES}, \mathrm{pH} 7.4$ adjusted with $\mathrm{CsOH}$ (Ochi et al., 2016). At a holding potential of $-80 \mathrm{mV}$, current-voltage relations were obtained by applying 500 -millisecond depolarization steps in $10-\mathrm{mV}$ increments at $0.2 \mathrm{~Hz}$ from -40 to $50 \mathrm{mV}$. The test potential initially depolarized from -80 to $-40 \mathrm{mV}$ to detect and inactivate the T-type $\mathrm{Ca}^{2+}$ channel current.

Statistical Analysis. Results are expressed as means \pm S.E.M. The relaxation was presented as percentage of the evoked contraction. Data were analyzed using GraphPad Prism software. Two-tailed Student's $t$ test was used for two group comparison. One-way analysis of variance with Newman-Keuls post-hoc test were used for statistical evaluation when more than two groups were compared. $P<0.05$ was taken as statistically significant.

\section{Results}

HDAC Inhibitors Reversed the Vascular Contraction Elicited by High Extracellular $\mathrm{K}^{+}$in Mouse Aortas. Exposure of aortic segments to high extracellular $\mathrm{K}^{+}$concentration at $60 \mathrm{mM}$ induced a rapid contraction of mouse aortas, which was completely reversed by an L-type $\mathrm{Ca}^{2+}$ channel inhibitor verapamil at $10 \mu \mathrm{M}$ (Fig. 1A). SAHA at $3-300 \mu \mathrm{M}$ or TSA at 1-100 $\mu \mathrm{M}$ induced dose-dependent relaxation in the arteries that were precontracted with high extracellular $\mathrm{K}^{+}$ (Fig. 1, B and C). Three hundred micromolar SAHA and 
A
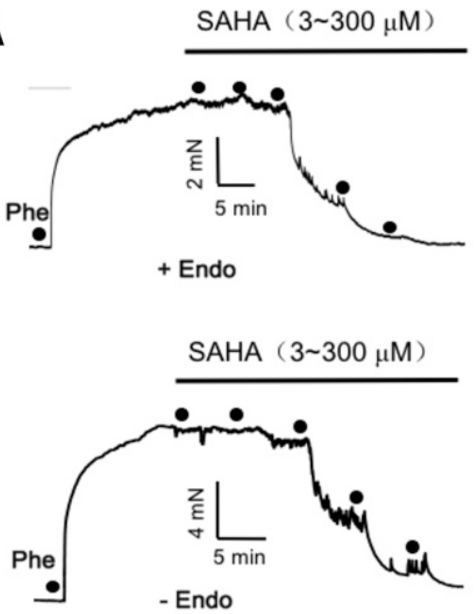

B
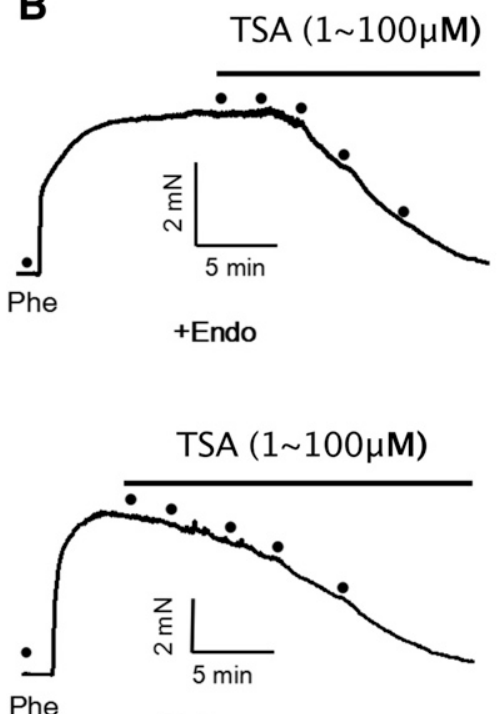

-Endo

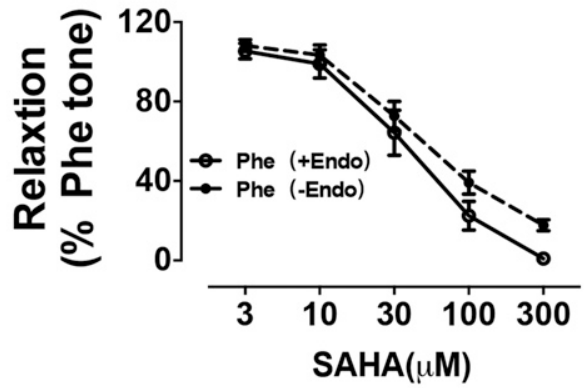

Fig. 4. HDAC inhibitors reversed the vascular contraction elicited by phenylephrine (Phe) in mouse aortas. Shown were vascular relaxant effect of SAHA (A) and TSA (B) on phenylephrine $(1 \mu \mathrm{M})$-precontracted aortas with endothelium (+Endo) or without endothelium (-Endo). Representative traces (left) and data summary (right) of relaxing effect are shown. The data are expressed as the mean \pm S.E.M. $(n=5)$.

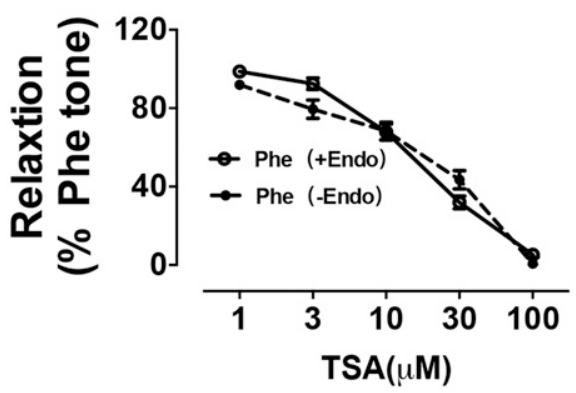

$100 \mu \mathrm{M}$ TSA resulted in a relaxation of $45 \% \pm 2 \%$ and $47 \% \pm$ $3 \%$, respectively (Fig. 1, B and C). The effect of SAHA and TSA was endothelium-independent (Fig. 1, B and C).

Several other HDAC inhibitors were also tested, including hydroxamates LBH-589 and PDX-101, as well as cyclic peptide FK-228. Like SAHA and TSA, all these HDAC inhibitors caused dose-dependent relaxation in high extracellular $\mathrm{K}^{+}$-contracted arteries (Supplemental Fig. 1).

TSA Attenuated the High Extracellular $\mathbf{K}^{+}$-Elicited Cytosolic $\mathrm{Ca}^{2+}$ Rise and Inhibited L-Type $\mathrm{Ca}^{2+}$ Channel Current. Cytosolic $\mathrm{Ca}^{2+}$ rise in response to high extracellular $\mathrm{K}^{+}$was measured in the freshly isolated mouse vascular smooth muscle cells. Sixty millimolar extracellular $\mathrm{K}^{+}$stimulated $\mathrm{Ca}^{2+}$ influx in these cells. Three hundred micromolar SAHA or $100 \mu \mathrm{M}$ TSA markedly attenuated the $\mathrm{Ca}^{2+}$ influx elicited by high extracellular $\mathrm{K}^{+}$(Fig. 2A).

Literature shows that hydroxamates such as TSA and SAHA are able to chelate multiple ions, including $\mathrm{Zn}^{2+}, \mathrm{Ni}^{2+}$, and $\mathrm{Fe}^{3+}$ (Hebbel et al., 2010; Griffith et al., 2011). In our experiments, $300 \mu \mathrm{M}$ SAHA or $100 \mu \mathrm{M}$ TSA had no significant effect on $1 \mu \mathrm{M}$ ionomycin-induced cytosolic $\mathrm{Ca}^{2+}$ rise in vascular smooth muscle cells (Fig. 2B), suggesting that the ability of these agents in chelating/buffering cytosolic $\mathrm{Ca}^{2+}$ was minimal, if any, in our experimental conditions.

Under high extracellular $\mathrm{K}^{+}$, L-type $\mathrm{Ca}^{2+}$ channel current is the major source of $\mathrm{Ca}^{2+}$, which initiates contraction of arterial smooth muscle cells and regulates blood pressure (Zhang et al., 2007). Whole-cell patch-clamp was used to measure L-type $\mathrm{Ca}^{2+}$ channel current. Because of technical difficulty in making giga-ohm seal on the plasma membrane of freshly isolated mouse smooth muscle cells, we opted to use A7r5 rat smooth muscle cells for patch-clamp studies. In whole-cell recording, the cells were held at $-80 \mathrm{mV}$ and voltage steps ranging from -40 to $+50 \mathrm{mV}$ were applied for 500 milliseconds in $10 \mathrm{mV}$ step increments. A typical U-shaped voltage-gated $\mathrm{Ca}^{2+}$ current was recorded in these cells (Fig. 2, C and D) (Sun et al., 2000). Application of $300 \mu \mathrm{M}$ SAHA or $100 \mu \mathrm{M}$ TSA substantially inhibited the voltagegated $\mathrm{Ca}^{2+}$ current in these cells (Fig. 2, C and D). 
A

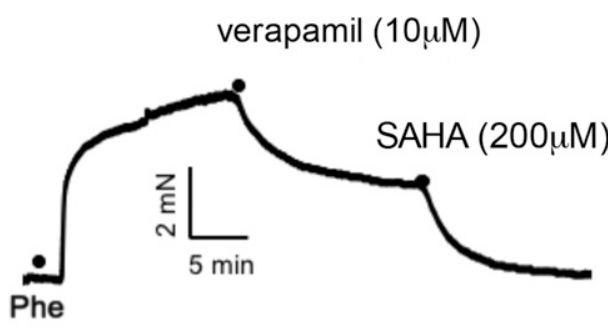

B

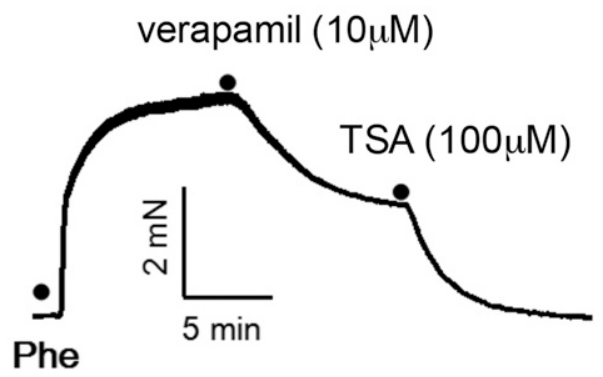

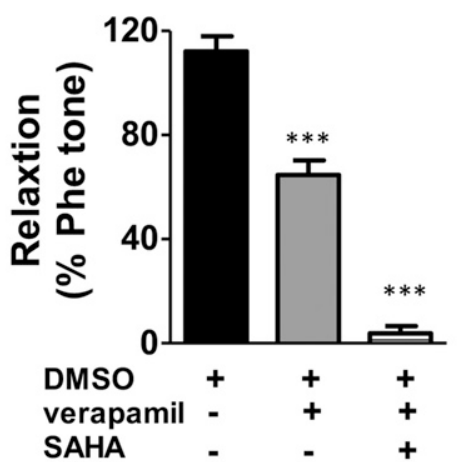

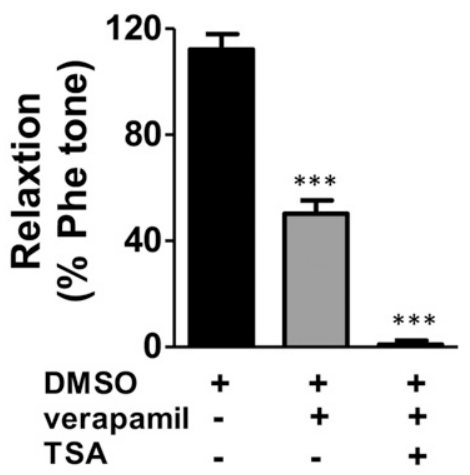

Fig. 5. Relative contribution of L-type $\mathrm{Ca}^{2+}$ channels vs. other components in the phenylephrine-precontracted arteries. The aortas were precontracted with $1 \mu \mathrm{M}$ phenylephrine (Phe), followed by $10 \mu \mathrm{M}$ verapamil. After the relaxant response to verapamil became stable, $200 \mu \mathrm{M}$ SAHA (A) or $100 \mu \mathrm{M}$ TSA (B) was added to induce further relaxation. Representative traces (left) and data summary (right) of relaxing effect are shown. The data are expressed as the mean \pm S.E.M. $(n=5) . * * * P<0.001$ vs. vehicle (DMSO) control.
Comparison of Inhibitory Potencies of TSA and SAHA on High Extracellular $\mathrm{K}^{+}$-Induced $\mathrm{Ca}^{2+}$ Entry with Their Vasodilatory Potencies. We examined the effect of different doses of SAHA $(3-300 \mu \mathrm{M})$ and TSA (1-100 $\mu \mathrm{M})$ on $\mathrm{Ca}^{2+}$ influx induced by high extracellular $\mathrm{K}^{+}$. The results showed that SAHA and TSA caused dosedependent inhibition on the high extracellular $\mathrm{K}^{+}$-induced $\mathrm{Ca}^{2+}$ influx with $\mathrm{IC}_{50}$ of 70 and $21 \mu \mathrm{M}$, respectively (Fig. 3, A and $\mathrm{B}$, left panels).

Dose-dependent vasodilatory curves of SAHA and TSA on high $\mathrm{K}^{+}$-precontracted mouse aortas were also plotted (Fig. 3, $\mathrm{A}$ and $\mathrm{B}$, right panels). The vasodilatory potencies of SAHA and TSA were similar to their inhibitory potencies on $\mathrm{Ca}^{2+}$ influx with comparable $\mathrm{IC}_{50}$ values (Fig. 3).

HDAC Inhibitors Reversed the Vascular Contraction Elicited by Phenylephrine in Mouse Aortas. SAHA at $3-300 \mu \mathrm{M}$ or TSA at $1-100 \mu \mathrm{M}$ also induced dose-dependent relaxation of mouse aortas precontracted with an $\alpha$-adrenergic receptor agonist phenylephrine at $1 \mu \mathrm{M}$ (Fig. 4, A and B). Compared with the high $\mathrm{K}^{+}$-contracted arteries, the relaxant effect of SAHA and TSA was greater in phenylephrinecontracted arteries. Three hundred micromolar SAHA and $100 \mu \mathrm{M}$ TSA almost completely reversed the phenylephrineinduced contraction (Fig. 4, A and B). Several other HDAC inhibitors, including PDX-101, LBH-589, and FK-228, also showed similar dose-dependent relaxation in phenylephrinecontracted arteries (Supplemental Fig. 1). In addition, the relaxant responses to SAHA and TSA were not significantly altered by endothelium denudation, suggesting that SAHA and TSA acted on vascular smooth muscle cells to exert their relaxant effect (Fig. 4, A and B).

Relative contribution of L-type $\mathrm{Ca}^{2+}$ channels versus other components in the phenylephrine-precontracted arteries was estimated. Application of $10 \mu \mathrm{M}$ verapamil caused $42-55 \%$ relaxation in these arteries (Fig. 5, A and B). Subsequent addition of $300 \mu \mathrm{M}$ SAHA or $100 \mu \mathrm{M}$ TSA resulted in further relaxation to nearly $100 \%$ (Fig. $5, \mathrm{~A}$ and $\mathrm{B}$ ). These data suggest that L-type $\mathrm{Ca}^{2+}$ channels accounted for $42-55 \%$ of the contraction and the remaining 45-58\% was independent of L-type $\mathrm{Ca}^{2+}$ channels.

SOCE Did Not Participate in the HADC InhibitorInduced Vascular Relaxation, but HADC Inhibitors Reduced the Phenylephrine-Induced Cytosolic $\mathrm{Ca}^{2+}$ Rise. The mechanisms of vascular contraction in response to vascular agonists are complicated, involving $\mathrm{Ca}^{2+}$ release from intracellular $\mathrm{Ca}^{2+}$ stores, $\mathrm{Ca}^{2+}$ entry through storeoperated $\mathrm{Ca}^{2+}$ influx and/or receptor-operated $\mathrm{Ca}^{2+}$ channels and/or L-type $\mathrm{Ca}^{2+}$ channels, as well as a sensitized contractile response to $\mathrm{Ca}^{2+}$ (Wang et al., 2008). We next explored whether HADC inhibitors could act on other mechanism(s) independent of L-type $\mathrm{Ca}^{2+}$ channels to induce vascular relaxation.

Calcium release-activated calcium channel protein 1 (Orai1) is the pore-forming subunit of SOCE in vascular smooth muscle cells (Lewis, 2011). As expected, the selective Orai1 inhibitor RO2959 at $200 \mathrm{nM}$ (Chen et al., 2013) greatly inhibited the SOCE in the acutely isolated mouse smooth muscle cells (Fig. 6A). However, RO2959 up to $5 \mu \mathrm{M}$ failed to induce relaxation in these arteries (Fig. 6B).

In the absence of extracellular $\mathrm{Ca}^{2+}$, application of $1 \mu \mathrm{M}$ phenylephrine failed to elicit a cytosolic $\mathrm{Ca}^{2+}$ rise (Fig. 7A), suggesting no significant stimulating effect of phenylephrine on intracellular $\mathrm{Ca}^{2+}$ release. Subsequent $\mathrm{Ca}^{2+}$ addback $(2 \mathrm{mM})$ to the bath solution resulted in a cytosolic $\mathrm{Ca}^{2+}$ rise, which was more marked in phenylephrine-treated cells than in DMSO-treated vehicle control (Fig. 7A, left panel), 


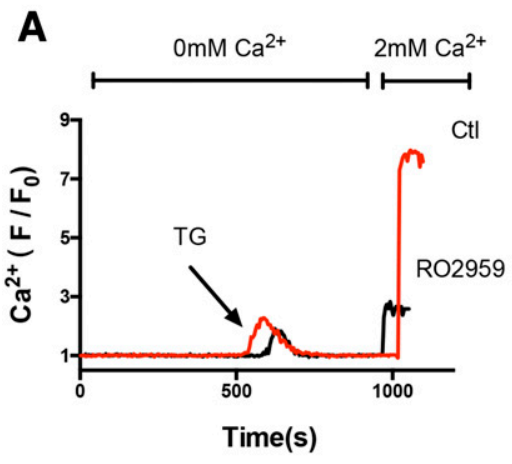

B
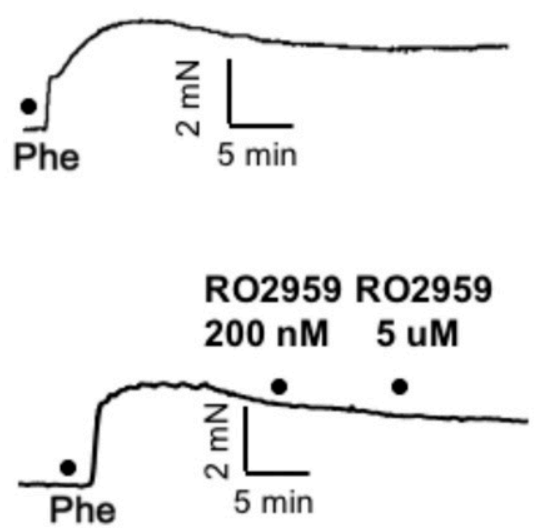

suggesting that phenylephrine elicited extracellular $\mathrm{Ca}^{2+}$ entry. As there was no obvious intracellular $\mathrm{Ca}^{2+}$ release in response to phenylephrine (Fig. 7A), this $\mathrm{Ca}^{2+}$ entry may reflect receptor-operated $\mathrm{Ca}^{2+}$ entry rather than SOCE. Importantly, in the presence of $100 \mu \mathrm{M}$ TSA or $300 \mu \mathrm{M}$ SAHA, the phenylephrine-elicited extracellular $\mathrm{Ca}^{2+}$ entry was abolished (Fig. 7A).

Dose-dependent inhibition of SAHA $(3-300 \mu \mathrm{M})$ and TSA (1-100 $\mu \mathrm{M})$ on phenylephrine-induced $\mathrm{Ca}^{2+}$ influx was determined (left panels in Fig. 7, B and C). Dose-dependent vasodilatory curves of SAHA and TSA on phenylephrineprecontracted mouse aortas were also plotted (right panels in Fig. 7, B and C). The inhibitory potencies of SAHA and TSA on $\mathrm{Ca}^{2+}$ influx were similar to their vasodilatory potencies with comparable $\mathrm{IC}_{50}$ values (Fig. $7, \mathrm{~B}$ and $\mathrm{C}$ ).

Lack of Nitric Oxide Involvement in TSA and SAHAInduced Vascular Relaxation. Methylene blue is a guanylate cyclase inhibitor commonly used to abolish nitric oxide-mediated vascular dilation (Gruetter et al., 1981). Preincubation with $10 \mu \mathrm{M}$ methylene blue for 15 minutes had no effect on SAHA-induced vascular relaxation in mouse aortas contracted with high extracellular $\mathrm{K}^{+}$(Fig. 8A) or phenylephrine (Fig. 8B), suggesting lack of nitric oxide involvement in SAHA-induced vascular relaxation.

\section{Discussion}

The main findings of the present study were as follows: 1) Two commonly used HDAC inhibitors, SAHA and TSA, partially reversed the high extracellular $\mathrm{K}^{+}$-induced contraction in mouse aortas. The effect of SAHA and TSA was acute, dose-dependent, but endothelium-independent. 2) SAHA and TSA also caused dose-dependent relaxation in phenylephrine-precontracted mouse aortas. Three hundred micromolar SAHA and $100 \mu \mathrm{M}$ TSA completely reversed the phenylephrine-induced contraction. Again, the effect of SAHA and TSA was acute and endothelium-independent. 3) In the freshly isolated mouse smooth muscle cells, SAHA and TSA markedly reduced the high $\mathrm{K}^{+}$-induced cytosolic $\mathrm{Ca}^{2+}$ rise. Whole-cell patch-clamp studies demonstrated that SAHA and TSA acutely inhibited the voltagegated L-type $\mathrm{Ca}^{2+}$ channel current in these cells. 4) SAHA and TSA also markedly reduced the phenylephrine-induced $\mathrm{Ca}^{2+}$ entry with inhibitory potency like their vasodilatory effect. 5) A potent Orai1 inhibitor, RO2959, failed to induce vascular relaxation in phenylephrine-induced contraction of mouse aortas. Taken together, the present study demonstrated that hydroxamate-based pan-HDAC inhibitors SAHA and TSA at intermediate micromolar concentrations could acutely inhibit L-type $\mathrm{Ca}^{2+}$ channels and consequently reduce the high extracellular $\mathrm{K}^{+}$-induced contraction of aortas. SAHA and TSA also relaxed the phenylephrine-precontracted aortas, a minor part of which could be attributed to the inhibitory effect of these compounds on L-type $\mathrm{Ca}^{2+}$ channels.

It is well documented that exposure to high extracellular $\mathrm{K}^{+}$ at 60-100 mM causes vascular contraction (Eto et al., 2001). The underlying mechanism involves high $\mathrm{K}^{+}$-induced membrane depolarization of vascular smooth muscle cells, which triggers an opening of voltage-gated $\mathrm{Ca}^{2+}$ channels, especially L-type $\mathrm{Ca}^{2+}$ channels. Subsequent $\mathrm{Ca}^{2+}$ influx through L-type $\mathrm{Ca}^{2+}$ channels elevates cytosolic $\mathrm{Ca}^{2+}$ level in vascular 


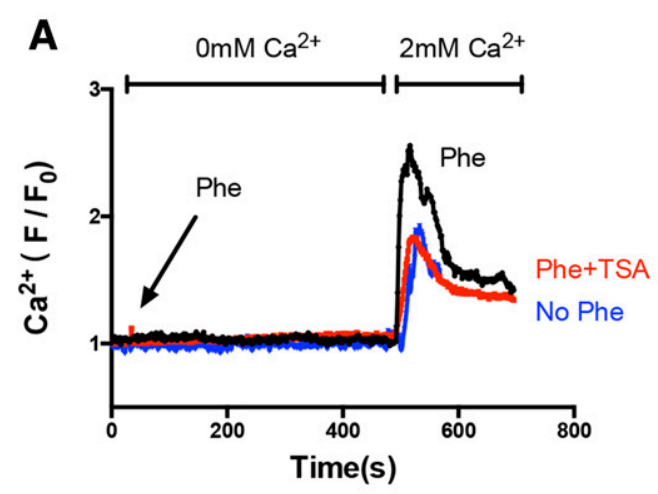

B

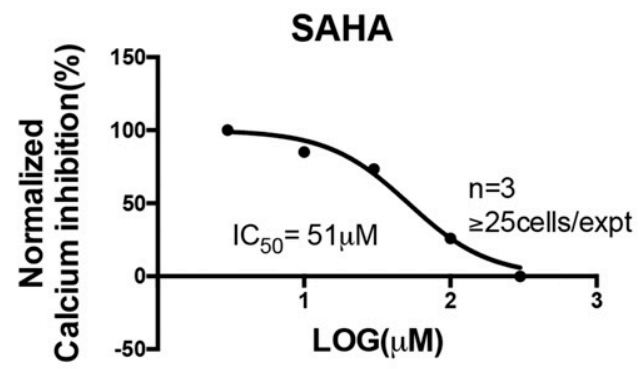

C

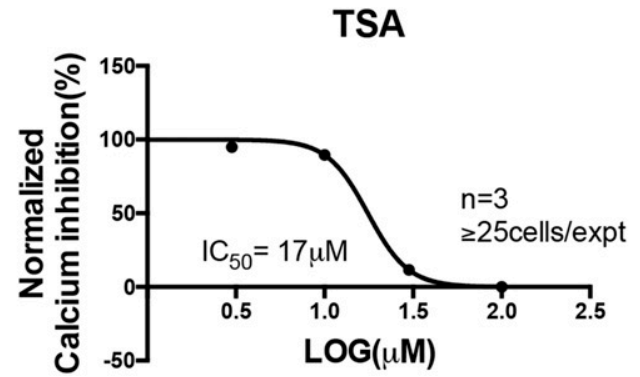

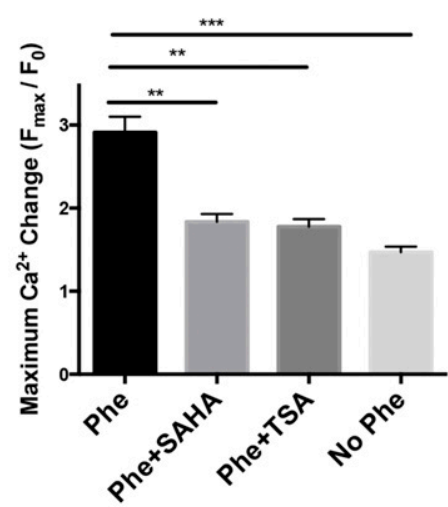

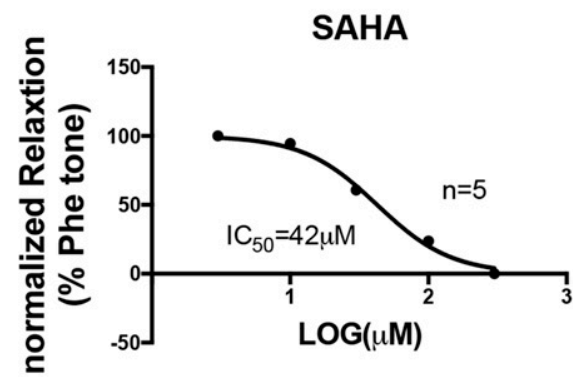

TSA

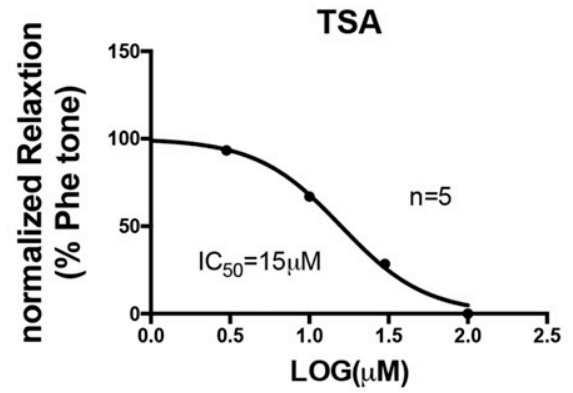

Fig. 7. Action of HDAC inhibitors on phenylephrine-induced cytosolic $\mathrm{Ca}^{2+}$ rise and comparison with their vasodilatory effect. (A) The freshly isolated mouse vascular smooth muscle cells were treated with $1 \mu \mathrm{M}$ phenylephrine (Phe) in a $\mathrm{Ca}^{2+}$-free bath, followed by adding back $2 \mathrm{mM} \mathrm{Ca}{ }^{2+}$ to the bath, which induced a $\mathrm{Ca}^{2+}$ entry. SAHA/TSA at $100 \mu \mathrm{M}$ was applied 2 minutes before Phe. The representative traces (left) and data summary (right) of Ca ${ }^{2+}$ responses are shown. (B) Comparison of dose-response curves and $\mathrm{IC}_{50}$ values of SAHA on Phe-induced cytosolic $\mathrm{Ca}^{2+}$ rise in smooth muscle cells (left panel) with vasodilatory action of SAHA in Phe-contracted mouse aortas (right panel). (C) Comparison of dose-response curves and IC 50 values of TSA on Phe-induced cytosolic $\mathrm{Ca}^{2+}$ rise in smooth muscle cells (left panel) with vasodilatory action of TSA in Phe-contracted mouse aortas (right panel). The summary data are expressed as the mean \pm S.E.M. $[n=5$ experiments, $>25$ cells per experiment in $(\mathrm{A}) ; n=3-5$ in $(\mathrm{B}$ and $\mathrm{C})]$. $* * P<0.01 ; * * * P<0.001$.

smooth muscle cells, resulting in vascular contraction (Eto et al., 2001). In the present study, high extracellular $\mathrm{K}^{+}$-induced aortic contraction was completely reversed by $10 \mu \mathrm{M}$ verapamil, confirming the involvement of L-type $\mathrm{Ca}^{2+}$ channels. Importantly, SAHA and TSA partially but acutely reversed the high extracellular $\mathrm{K}^{+}$-induced contraction of mouse aortas, suggesting a possible inhibitory action of these agents on voltage-gated $\mathrm{Ca}^{2+}$ channels. Two sets of experiments, cytosolic $\mathrm{Ca}^{2+}$ measurement and whole-cell patchclamp, were performed to verify the action of SAHA and TSA on L-type $\mathrm{Ca}^{2+}$ channels. In cytosolic $\mathrm{Ca}^{2+}$ measurement, high extracellular $\mathrm{K}^{+}$-evoked cytosolic $\mathrm{Ca}^{2+}$ rise was reduced by SAHA and TSA. Whole-cell patch-clamp experiments provide the direct evidence for inhibitory action of SAHA and TSA on L-type $\mathrm{Ca}^{2+}$ channel current in vascular smooth muscle cells. Interestingly, inhibitory potencies $\left(\mathrm{IC}_{50}\right)$ of $\mathrm{SAHA}$ and
TSA on high extracellular $\mathrm{K}^{+}$-induced $\mathrm{Ca}^{2+}$ rise were similar to the vasodilatory potencies of these compounds in high $\mathrm{K}^{+}$-contracted arteries. Taken together, these results provided unequivocal evidence for inhibitory action of HDAC inhibitors on the activity of L-type $\mathrm{Ca}^{2+}$ channels in vascular smooth muscle cells.

Our finding about the modulatory effect of HDAC inhibitors on voltage-gated $\mathrm{Ca}^{2+}$ channels has important physiologic and pathologic implication. SAHA and several other HDAC inhibitors are in clinical use for cancer treatment (Zwergel et al., 2016). In animal models, HDAC inhibitors also show beneficial cardiovascular effect by alleviating cardiac hypertrophy, hypertension, and myocardial infraction (Eom and Kook, 2014). In the present study, we show for the first time that HDAC inhibitors can acutely inhibit L-type $\mathrm{Ca}^{2+}$ channels and subsequently reduce the vascular tone. It is well 

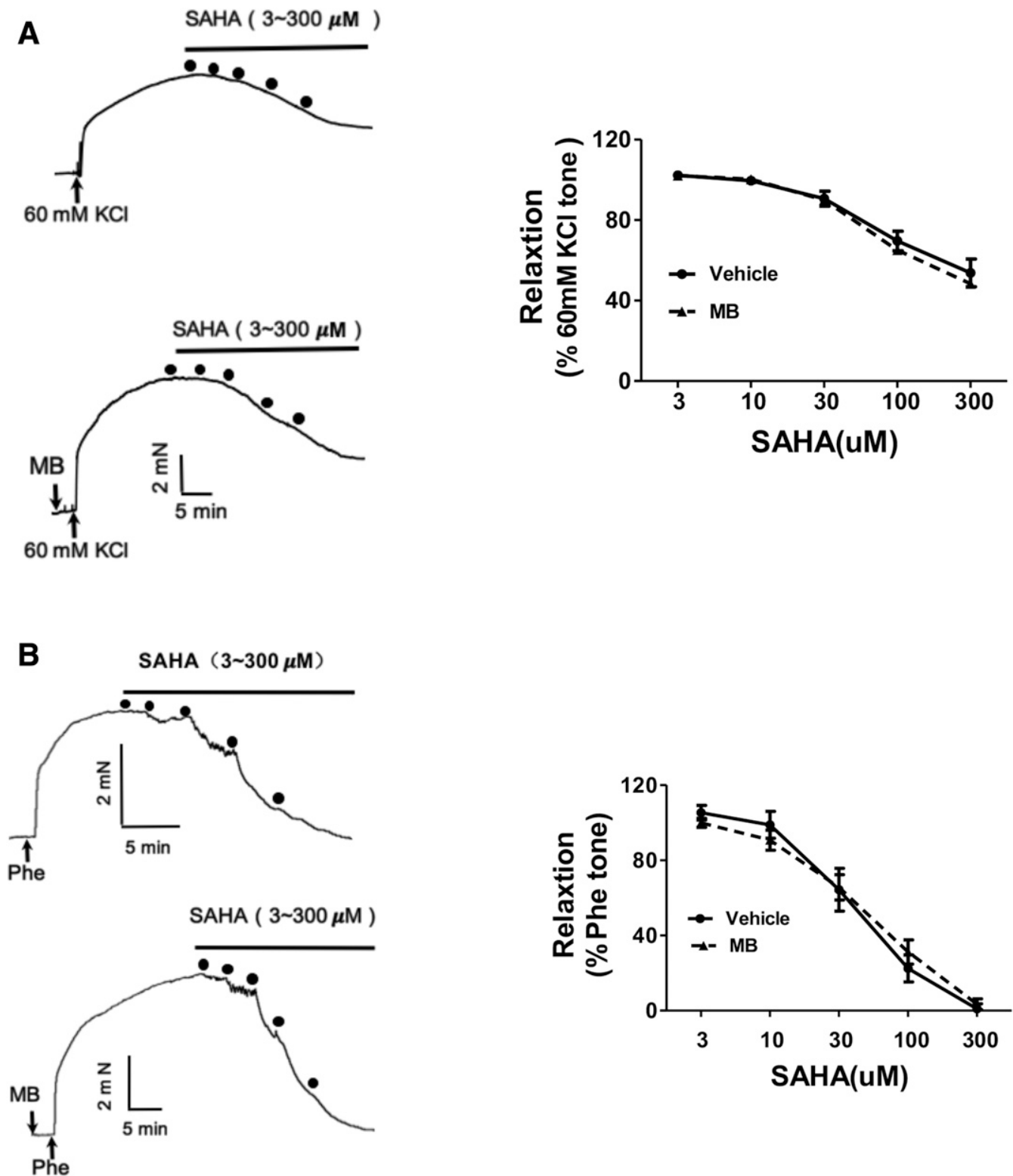

Fig. 8. Nitric oxide did not contribute to HADC inhibitor-induced vascular relaxation. (A) The aortas were precontracted with $60 \mathrm{mM} \mathrm{KCl}$ in the absence (upper left panel) or presence (lower left panel) of $10 \mu \mathrm{M}$ methylene blue (MB). After the contractile response became stable ( 10 minutes), SAHA was added to induce relaxation. (B) The aortas were precontracted with $1 \mu \mathrm{M}$ phenylephrine in the absence (upper left panel) or presence (lower left panel) of $10 \mu \mathrm{M}$ methylene blue (MB). After the contractile response became stable ( 10 minutes), SAHA was added to induce relaxation. Shown are representative traces (left) and data summary (right). The data are expressed as the mean \pm S.E.M. $(n=5)$.

documented that L-type $\mathrm{Ca}^{2+}$ channels are closely associated with vascular tone and that an aggravated activity of L-type $\mathrm{Ca}^{2+}$ channels is a causative factor for pathologic progression of hypertrophy, hypertension, and myocardial infraction (Nayler, 1993). Therefore, our present results about the effect of HDAC inhibitors on L-type $\mathrm{Ca}^{2+}$ channels may provide a mechanistic explanation for cardio-protective effect of HDAC inhibitors against hypertrophy, hypertension, and myocardial infraction.

The mechanisms of vascular contraction in response to vascular agonists such as phenylephrine are complicated. These may include $\mathrm{Ca}^{2+}$ release from intracellular $\mathrm{Ca}^{2+}$ stores, $\mathrm{Ca}^{2+}$ entry through store-operated $\mathrm{Ca}^{2+}$ influx and/or receptoroperated $\mathrm{Ca}^{2+}$ channels and/or L-type $\mathrm{Ca}^{2+}$ channels, as well as a sensitized contractile response to $\mathrm{Ca}^{2+}$ (Nishimura et al., 1989;
Sun et al., 2000). In our study, SAHA and TSA could completely reverse the phenylephrine-induced contraction in mouse aorta. As expected, part of the phenylephrine-induced contraction, which amounts to $42-55 \%$, was mediated by L-type $\mathrm{Ca}^{2+}$ channels (Nishimura et al., 1989), as indicated by its sensitivity to verapamil inhibition. However, in the presence of verapamil, SAHA and TSA could cause additional relaxation, which presumably resulted from other mechanisms independent of L-type $\mathrm{Ca}^{2+}$ channels. In our studies, phenylephrine failed to elicit significant intracellular $\mathrm{Ca}^{2+}$ release (Fig. 7A). Furthermore, inhibition of SOCE by an Orai1 inhibitor RO2959 failed to reverse the phenylephrine-induced contraction (Fig. 6B). These data suggest that the vascular relaxant effect of SAHA and TSA was independent of intracellular $\mathrm{Ca}^{2+}$ release or SOCE. Nevertheless, SAHA and TSA could inhibit phenylephrine-elicited 
$\mathrm{Ca}^{2+}$ entry. Furthermore, inhibitory potencies $\left(\mathrm{IC}_{50}\right)$ of SAHA and TSA on phenylephrine-induced $\mathrm{Ca}^{2+}$ entry were similar to the vasodilatory potencies of these compounds in phenylephrine-contracted arteries, suggesting an important role of cytosolic $\mathrm{Ca}^{2+}$ in these events. Together, these data suggest a possible action of HDAC inhibitors on some $\mathrm{Ca}^{2+}$-signaling mechanisms independent of SOCE and intracellular $\mathrm{Ca}^{2+}$ release. These may include receptor-operated $\mathrm{Ca}^{2+}$ entry, $\mathrm{Ca}^{2+}$ sensitivity of contractile mechanism, or other alternative mechanisms.

One concern is that under oxidative stress, hydroxamate compounds, including SAHA and TSA, are able to produce nitric oxide (Samuni et al., 2009), which could account for the vasodilatory action of these compounds. However, all our experiments, including vascular tone studies and $\mathrm{Ca}^{2+}$ entry and patch-clamp experiments, were performed under normal physiologic saline without oxidative stress. Indeed, pretreatment of arteries with methylene blue, a guanylate cyclase inhibitor, had no effect on SAHA-induced vascular dilation, suggesting that the vasodilatory response to hydroxamate compounds in our experiments was not the result of hydroxamate-generated nitric oxide.

SAHA and TSA are pan-HDAC inhibitors that inhibit class I and class II HDAC proteins. However, their inhibitory potency to different classes of HDAC proteins varies greatly (Dokmanovic et al., 2007; Ko et al., 2013; Lobera et al., 2013). The reported IC $_{50}$ values of SAHA and TSA for class I and class IIb HDAC proteins range from nanomolar to sub-micromolar, whereas the $\mathrm{IC}_{50}$ values for class IIa HDAC proteins range from low to intermediate micromolar (Dokmanovic et al., 2007; Ko et al., 2013; Lobera et al., 2013). In our studies, SAHA and TSA relaxed the extracellular high $\mathrm{K}^{+}$- and phenylephrine-precontracted aortas at intermediate micromolar concentration, which could inhibit class IIa HDAC proteins. However, considering the issue of drug permeation in cultured cells and vascular tissue, it is still uncertain which specific class of HDAC proteins might be involved.

In conclusion, we have demonstrated that HDAC inhibitors can cause acute inhibition of the activity of L-type $\mathrm{Ca}^{2+}$ channels, resulting in partial reversal of high extracellular $\mathrm{K}^{+}$-induced vascular contraction. HDAC inhibitors also acutely and potently reverse the phenylephrine-induced vascular contraction via L-type $\mathrm{Ca}^{2+}$ channel-dependent and -independent mechanisms.

\section{Acknowledgments}

The authors thank Dr. Jiangyun Luo, Zhiheng Liu, and Cheng Chen for comments that greatly improved the manuscript.

\section{Authorship Contributions}

Participated in research design: Zheng, Zhong, Huang, Tsang, Yao. Conducted experiments: Zhong, Zheng, Qi, Shen, Zhao, Wu.

Performed data analysis: Zhong, Zheng, Qi.

Wrote or contributed to the writing of the manuscript: Yao, Zhong, Zheng, Qi, Huang, Tsang.

\section{References}

Chen G, Panicker S, Lau KY, Apparsundaram S, Patel VA, Chen SL, Soto R, Jung JKC, Ravindran P, Okuhara D, et al. (2013) Characterization of a novel CRAC inhibitor that potently blocks human T cell activation and effector functions. Mol Immunol 54:355-367.

Choudhary C, Kumar C, Gnad F, Nielsen ML, Rehman M, Walther TC, Olsen JV, and Mann M (2009) Lysine acetylation targets protein complexes and co-regulates major cellular functions. Science 325:834-840.
Colussi C, Scopece A, Vitale S, Spallotta F, Mattiussi S, Rosati J, Illi B, Mai A, Castellano S, Sbardella G, et al. (2012) P300/CBP associated factor regulates nitroglycerin-dependent arterial relaxation by $\mathrm{N}(\varepsilon)$-lysine acetylation of contractile proteins. Arterioscler Thromb Vasc Biol 32:2435-2443.

Dokmanovic M, Clarke C, and Marks PA (2007) Histone deacetylase inhibitors: overview and perspectives. Mol Cancer Res 5:981-989.

Eom GH and Kook H (2014) Posttranslational modifications of histone deacetylases: implications for cardiovascular diseases. Pharmacol Ther 143:168-180.

Eto K, Ohya Y, Nakamura Y, Abe I, and Fujishima M (2001) Comparative actions of insulin sensitizers on ion channels in vascular smooth muscle. Eur J Pharmacol 423:1-7.

Griffith DM, Szocs B, Keogh T, Suponitsky KY, Farkas E, Buglyó P, and Marmion CJ (2011) Suberoylanilide hydroxamic acid, a potent histone deacetylase inhibitor; its X-ray crystal structure and solid state and solution studies of its $\mathrm{Zn}(\mathrm{II}), \mathrm{Ni}(\mathrm{II})$ $\mathrm{Cu}(\mathrm{II})$ and $\mathrm{Fe}(\mathrm{III})$ complexes. J Inorg Biochem 105:763-769.

Gruetter CA, Gruetter DY, Lyon JE, Kadowitz PJ, and Ignarro LJ (1981) Relationship between cyclic guanosine $3^{\prime}: 5^{\prime}$-monophosphate formation and relaxation of coronary arterial smooth muscle by glyceryl trinitrate, nitroprusside, nitrite and nitric oxide: effects of methylene blue and methemoglobin. J Pharmacol Exp Ther 219:181-186.

Hebbel RP, Vercellotti GM, Pace BS, Solovey AN, Kollander R, Abanonu CF, Nguyen J, Vineyard JV, Belcher JD, Abdulla F, et al. (2010) The HDAC inhibitors trichostatin A and suberoylanilide hydroxamic acid exhibit multiple modalities of benefit for the vascular pathobiology of sickle transgenic mice. Blood 115: $2483-2490$.

Kang G, Lee YR, Joo HK, Park MS, Kim CS, Choi S, and Jeon BH (2015) Trichostatin a modulates angiotensin II-induced vasoconstriction and blood pressure via inhibition of p66shc activation. Korean J Physiol Pharmacol 19:467-472.

Ko KS, Steffey ME, Brandvold KR, and Soellner MB (2013) Development of a chimeric c-Src kinase and HDAC inhibitor. ACS Med Chem Lett 4:779-783.

Lewis RS (2011) Store-operated calcium channels: new perspectives on mechanism and function. Cold Spring Harb Perspect Biol 3(12) DOI: 10.1101/cshperspect. a003970.

Mathews KS, Corso P, Bacon S, and Jenq GY (2014) Using the red/yellow/green discharge tool to improve the timeliness of hospital discharges. Jt Comm J Qual Patient Saf 40:243-252.

Nayler WG (1993) Pharmacological aspects of calcium antagonism. Short term and long term benefits. Drugs 46 (Suppl 2):40-47.

Nishimura J, Khalil RA, and van Breemen C (1989) Agonist-induced vascular tone. Hypertension 13 (6 Pt 2):835-844.

Ochi R, Dhagia V, Lakhkar A, Patel D, Wolin MS, and Gupte SA (2016) Rotenonestimulated superoxide release from mitochondrial complex I acutely augments L-type Ca2+ current in A7r5 aortic smooth muscle cells. Am J Physiol Heart Circ Physiol 310:H1118-H1128.

Pandey D, Sikka G, Bergman Y, Kim JH, Ryoo S, Romer L, and Berkowitz D (2014) Transcriptional regulation of endothelial arginase 2 by histone deacetylase 2 . Arterioscler Thromb Vasc Biol 34:1556-1566.

Qi Y, Qi Z, Li Z, Wong C-K, So C, Lo I-C, Huang Y, Yao X, and Tsang S-Y (2015) Role of TRPV1 in the differentiation of mouse embryonic stem cells into cardiomyocytes. PLoS One 10:e133211.

Richardson PG, Moreau P, Laubach JP, Maglio ME, Lonial S, and San-Miguel J (2017) Deacetylase inhibitors as a novel modality in the treatment of multiple myeloma. Pharmacol Res 117:185-191.

Samuni Y, Flores-Santana W, Krishna MC, Mitchell JB, and Wink DA (2009) The inhibitors of histone deacetylase suberoylanilide hydroxamate and trichostatin A release nitric oxide upon oxidation. Free Radic Biol Med 47:419-423.

Sun L, Fan JS, Clark JW, and Palade PT (2000) A model of the L-type Ca2+ channel in rat ventricular myocytes: ion selectivity and inactivation mechanisms. J Physiol 529:139-158.

Tian XY, Wong WT, Wang N, Lu Y, Cheang WS, Liu J, Liu L, Liu Y, Lee SST, Chen ZY, et al. (2012) PPAR $\delta$ activation protects endothelial function in diabetic mice. Diabetes 61:3285-3293.

Usui T, Okada M, Mizuno W, Oda M, Ide N, Morita T, Hara Y, and Yamawaki H (2012) HDAC4 mediates development of hypertension via vascular inflammation in spontaneous hypertensive rats. Am J Physiol Heart Circ Physiol 302: H1894-H1904.

Wang Y, Deng X, Hewavitharana T, Soboloff J, and Gill DL (2008) Stim, ORAI and TRPC channels in the control of calcium entry signals in smooth muscle. Clin Exp Pharmacol Physiol 35:1127-1133.

Zhang J, Berra-Romani R, Sinnegger-Brauns MJ, Striessnig J, Blaustein MP, and Matteson DR (2007) Role of Cav1.2 L-type Ca2+ channels in vascular tone: effects of nifedipine and $\mathrm{Mg} 2+. \mathrm{Am} J$ Physiol Heart Circ Physiol 292: $\mathrm{H} 415-\mathrm{H} 425$.

Zwergel C, Stazi G, Valente S, and Mai A (2016) Histone deacetylase inhibitors: updated studies in various epigenetic - related diseases. J Clin Epigenetics 2:1-15.

Address correspondence to: Dr. Mingkui Zhong, Department of Physiology, Anhui Medical University, Hefei 230032, China. E-mail: mingkuizhong@ahmu. edu.cn; or, Dr. Xiaoqiang Yao, School of Biomedical Sciences, The Chinese University of Hong Kong, Shatin, Hong Kong SAR, China. E-mail: yao2068@ cuhk.edu.hk. 